\title{
ANALISIS KESESUAIAN LAHAN TAMBAK BERDASARKAN PARAMETER FISIS \& CHEMIS UNTUK BUDIDAYA KEPITING BAKAU (Scylla spp) DI KELURAHAN DEGAYU KOTA PEKALONGAN
}

\author{
Hisyam Abdurrahman Risa, Hadi Pranggono, Tri Yusufi Mardiana \\ Program Studi Budidaya Perairan Fakultas Perikanan Universitas Pekalongan
}

\begin{abstract}
This study is to determine the level of land suitability as well as assessing the extent to which the potential of land resources can be utilized for the cultivation of mangrove crabs. The purpose of this research is to know the level of land suitability based on physical and chemical parameters for the cultivation of mangrove crab in the pond area in Degayu Village. This research was conducted on 4 until 9 June 2018 at 4 ponds in Degayu Village. Water parameters measured are temperature, salinity, water $\mathrm{pH}, \mathrm{DO}$, ammonia, nitrate, phosphate, soil texture, soil $\mathrm{pH}$. The feasibility analysis of pond land is done by using Scoring Method with 3 values of feasibility class interval that is very suitable (S1), according (S2), not appropriate (S3). The result from 4 point of pond station representing Degayu Subdistrict showed temperature value ranged from $31-34^{\circ} \mathrm{C}$, salinity ranged between $18-28 \mathrm{ppt}$, water $\mathrm{pH}$ ranged from 6,3-7,9 ppm, DO ranged from 3.0-6,0 ppm, ammonia ranged from 0.1-0.3 mg/l, nitrate ranged from 1.4 to $1.8 \mathrm{mg} / 1$, phosphate ranged from $1-2 \mathrm{mg} / 1$, soil texture was generally dominated by a mixture of clay / clay, sand, and dust and soil $\mathrm{pH}$ ranges from 7.0-7.5. At station 1,3 gets $\mathrm{S} 1$ value (very suitable) while station $2,4 \mathrm{a}$, and $4 \mathrm{~b}$ got $\mathrm{S} 2$ value (accordingly). Pond in Degayu village has a category of appropriate feasibility class (S1) to support the activities of mangrove crab cultivation.
\end{abstract}

Keywords: Crab, Land suitability, Water quality and soil parameters

\section{PENDAHULUAN}

Kepiting bakau (Scylla spp) merupakan salah satu jenis spesies ikan yang potensinya cukup baik untuk dikembangkan. Menurut data yang diperoleh dari Badan Pusat Statistik (BPS, 2017), ekspor kepiting dan kerang-kerangan dari tahun ke tahun mengalami peningkatan, beberapa negara tujuan ekspor seperti Tiongkok, Taiwan, Amerika Serikat, Italia, Malaysia, dll. Tiongkok menjadi negara tujuan ekspor nomor 1 dengan jumlah 42683,9 ton pada tahun 2015 yang sebelumnya pada tahun tahun 2014 sebanyak 34167,8 ton hal ini menunjukkan terus meningkatnya permintaan kepiting di pasar global.

Kebutuhan konsumen akan kepiting bakau selama ini sebagian besar masih dipenuhi dari hasil penangkapan di alam yang sifatnya fluktuatif. Daya dukung lingkungan yang semakin berkurang dan penangkapan yang dilakukan di alam terjadi secara terus menerus, mengakibatkan terjadinya penurunan populasi kepiting bakau di alam dan produksi kepiting bakau pun mengalami penurunan (Mossa dkk, 1995).

Kelurahan Degayu adalah salah satu kelurahan di wilayah Kecamatan Pekalongan Utara yang menyimpan potensi sumberdaya pesisir dan kelautan, baik hayati ataupun nonhayati yang cukup besar dan sangat menjanjikan untuk dikelola salah satunya potensi perikanan budidaya khususnya tambak. Pengembangan budidaya air payau menjadi andalan usaha perikanan yang dilihat dari banyaknya areal tambak baik yang produktif maupun yang terlantar. Penurunan kualitas tambak akibat dari rob yang merendam beberapa tahun lalu menjadikan lahan tambak kurang produktif untuk budidaya. Oleh karena itu diperlukan suatu upaya pemanfaatan lahan tambak untuk budidaya kepiting bakau agar berlangsung baik, untuk mendukung upaya tersebut maka perlu dilakukan 
penelitian tentang analisis kesesuaian lahan berdasarksn psrsmeter fisis dan chemis. Tujuan penelitian ini adalah mengetahui tingkat kesesuaian lahan berdasarkan parameter fisis dan chemis untuk budidaya kepiting bakau pada lahan tambak yang ada di Kelurahan Degayu.

\section{TINJAUAN PUSTAKA}

Menurut Rossiter (1996), evaluasi kesesuaian lahan sangat penting dilakukan karena lahan memiliki sifat fisik, sosial, ekonomi, dan geografi yang bervariasi atau lahan diciptakan tidak sama. Evaluasi kesesuaian lahan dapat memprediksi keragaan lahan dalam hal keuntungan yang diharapkan dari penggunaan lahan dan kendala penggunaan lahan yang produktif serta degradasi lingkungan yang diperkirakan akan terjadi karena penggunaan lahan. Kesesuaian lahan merupakan suatu kunci sukses dalam kegiatan akuakultur yang mempengaruhi kesuksesan dan keberlanjutannya serta dapat memecahkan konflik antara berbagai kegiatan dan membuat penggunaan lahan lebih rasional (Pérez et al., 2003)

\section{METODE PENELITIAN}

Penelitian ini dilaksanakan pada tanggal 4 sampai 9 Juni 2018 di tambak Kelurahan Degayu. Pengambilan sampel air dan tanah dilakukan di 4 stasiun tambak yaitu 1,2,3,4a, dan 4b. Metode yang digunakan dalam penelitian ini adalah survei yang didasarkan pada pendekatan secara deskriptif. metode deskriptif ialah suatu metode dalam meneliti status suatu kelas peristiwa pada masa sekarang. Tujuannya ialah untuk membuat deskripsi atau gambaran secara sistematis faktual dan akurat tentang fakta - fakta dan sifat-sifat serta hubungan antara fenomena yang diselidiki. (Nasir, 1983).

Parameter kualitas air dan tanah yang diukur meliputi salinitas, pH, DO, nitrat, fosfat, ammonia, tekstur tanah, dan $\mathrm{pH}$ tanah. Setiap parameter tersebut diambil sebanyak $3 \mathrm{x}$ ulangan kecuali tekstur tanah hanya $1 \mathrm{x}$ ulangan untuk selanjutnya dilakukan pengukuran di lapangan maupun di laboratorium.

Data yang telah diperoleh baik dari sampel air dan tanah akan dibandingkan dengan baku mutu yang telah ditentukan sebagai standar. Lebih lanjut lagi dapat dilakukan pengkategorian kelas kelayakan lahan tambak dengan menggunakan metode pembobotan/scoring. Penilaian kelayakan variabel didasarkan pada tingkat pengaruhnya terhadap kondisi lingkungan tambak sebagai persyaratan dalam kehidupan juga pertumbuhan kepiting bakau. Nilai variabel tersebut disajikan pada Tabel 1. Kelayakan kualitas air dan tanah untuk budidaya kepiting bakau disajikan pada Tabel 2.

Tabel 1. Kisaran Parameter Kualitas Air dan Tanah untuk Budidaya Kepiting di Tambak

\begin{tabular}{|c|c|c|c|c|c|}
\hline \multirow{2}{*}{ Variabel } & \multirow{2}{*}{ Bobot } & \multicolumn{3}{|c|}{ Kisaran Kualitas Air dan Tanah } & \multirow{2}{*}{ Referensi } \\
\hline & & Baik (5) & Sedang (3) & Buruk (1) & \\
\hline Suhu $\left({ }^{\circ} \mathrm{C}\right)$ & 3 & $25-30$ & $\begin{array}{c}18-24 \& \\
31-32\end{array}$ & $<18 \&>32$ & KMLH (2004) \\
\hline Salinitas (ppt) & 3 & $15-25$ & $\begin{array}{c}10-14 \& \\
26-30\end{array}$ & $<10 \&>30$ & $\begin{array}{l}\text { Buwono (1993); } \\
\text { Ramelan(1994); }\end{array}$ \\
\hline $\mathrm{pH}$ air & 2 & $7,5-8,5$ & $6-7,4$ & $<6$ atau $>8,5$ & $\begin{array}{l}\text { William (2003). } \\
\text { KMLH (2004) }\end{array}$ \\
\hline $\begin{array}{l}\text { Oksigen } \\
\text { Terlarut (ppm) }\end{array}$ & 3 & $>4$ & $3-4$ & $<3$ & $\begin{array}{l}\text { Ramelan(1994); } \\
\text { William (2003). }\end{array}$ \\
\hline
\end{tabular}




\begin{tabular}{|c|c|c|c|c|c|}
\hline Amoniak (ppm) & 2 & $<0,3$ & $0,3-0,5$ & $>0,5$ & Clifford (1992) \\
\hline Nitrat (ppm) & 2 & $0,01-10$ & $\begin{array}{c}0,001-0,01 \\
\& 10-20\end{array}$ & $<0,001 \&>20$ & $\begin{array}{l}\text { PP RI No. } 82 \text { tahun } \\
2001 .\end{array}$ \\
\hline Fosfat (ppm) & 2 & $0,2-0,5$ & $0,6-0,8$ & $<0,2 \&>0,8$ & Boyd, 1982. \\
\hline Tekstur Tanah & 2 & $\begin{array}{l}\text { Tipe } \\
\text { halus }\end{array}$ & Tipe sedang & Tipe kasar & William (2003). \\
\hline Variabel & Bobot & $\begin{array}{r}\text { Kisar } \\
\text { Baik (5) }\end{array}$ & \multicolumn{2}{|c|}{ Kisaran Kualitas Air dan Tanah } & Referensi \\
\hline pH Tanah & 2 & $6,5-8,5$ & $5-6,4$ & $<5$ & $\begin{array}{c}\text { Adhikari (2003); } \\
\text { Karthik et al. }(2005) .\end{array}$ \\
\hline
\end{tabular}

Sumber: Agus (2008); Syafikri \& Neri (- -) dengan beberapa modifikasi

Tabel 2. Nilai dan Bobot Variabel Lingkungan Tambak Berdasarkan Parameter Fisis dan Chemis untuk Kelayakan Budidaya Kepiting di Tambak

\begin{tabular}{cccccc}
\hline Variabel & Nilai Min. & $\begin{array}{c}\text { Nilai } \\
\text { Maks. }\end{array}$ & Bobot & $\begin{array}{c}\text { Total Nilai } \\
\text { Min. }\end{array}$ & $\begin{array}{c}\text { Total Nilai } \\
\text { Maks. }\end{array}$ \\
\hline Suhu & 1 & 5 & 3 & 3 & 15 \\
\hline Salinitas (ppt) & 1 & 5 & 3 & 3 & 15 \\
\hline pH air & 1 & 5 & 2 & 2 & 10 \\
\hline Oksigen Terlarut (ppm) & 1 & 5 & 3 & 3 & 15 \\
\hline Amoniak (ppm) & 1 & 5 & 2 & 2 & 10 \\
\hline Nitrat (ppm) & 1 & 5 & 2 & 2 & 10 \\
\hline Fosfat (ppm) & 1 & 5 & 2 & 2 & 10 \\
\hline Tekstur Tanah & 1 & 5 & 2 & 2 & 10 \\
\hline pH Tanah & 1 & 5 & 2 & 2 & 10 \\
\hline Total & & & & 21 & 105 \\
\hline Sun
\end{tabular}

Sumber: Agus (2008) dengan beberapa modifikasi

Selanjutnya dilakukan pembagian interval kelas kelayakan menjadi 3 kelas kelayakan yaitu ; sangat sesuai (S1), layak (S2) dan tidak layak (3) berdasarkan rumus metode Equal Interval (Irianto, 2007 dan Prahasta, 2002). Berikut rumus metode Equal Interval yaitu :

$$
\begin{aligned}
& \mathrm{I}=\frac{(\Sigma \text { ai.Xn }) \max -(\Sigma \text { ai.Xn }) \mathrm{min}}{\mathrm{K}} \\
& \mathrm{I}=\frac{105-21}{3}=28
\end{aligned}
$$

Berdasarkan rumus metode equal interval maka diperoleh interval klas kelayakan kualitas air dan tanah untuk budidaya kepiting bakau sebagai berikut :

Tabel 3. Interval Kelas Kelayakan Lahan Tambak

\begin{tabular}{ccl}
\hline Interval & Kategori & \multicolumn{1}{c}{ Keterangan } \\
\hline $77-105$ & Sangat Sesuai (S1) & $\begin{array}{l}\text { Kualitas air dan tanah } \\
\text { sangat layak }\end{array}$ \\
\hline $49-76,9$ & Sesuai (S2) & $\begin{array}{l}\text { Kualitas air dan tanah layak } \\
\text { dengan kategori sedang }\end{array}$ \\
\hline $21-48,9$ & Tidak Sesuai (S3) & $\begin{array}{l}\text { Kualitas air dan tanah tidak } \\
\text { layak }\end{array}$ \\
\hline
\end{tabular}


Selanjutnya data yang telah terkumpul dianalisis secara deskriptif sehingga bisa menggambarkan apakah tambak yang ada di Kelurahan Degayu layak atau tidak berdasarkan parameter fisis dan chemis untuk budidaya kepiting.

\section{HASIL DAN PEMBAHASAN}

Data hasil pengukuran kualitas air dan tanah disajikan dalam bentuk tabel dan selanjutnya dilakukan perhitungan pembobotan/scoring. Total skor dari hasil kali nilai variabel dengan bobotnya tersebut digunakan untuk menentukan interval klas kelayakan lahan tambak. Penilaian parameter kualitas air dan tanah berdasarkan referensi seperti tertera pada Tabel 1. Adapun hasil pengukuran kualitas air dan tanah setiap stasiun tersaji dalam Tabel 4-8. Dan kelas kelayakan lahan tambak di Kelurahan Degayu dapat dilihat pada tabel 9.

Tabel 4. Data Analisa Kelayakan Tambak Stasiun 1

\begin{tabular}{|c|c|c|c|c|c|c|}
\hline No & Parameter & Hasil Pengukuran & $\begin{array}{l}\text { Angka } \\
\text { Penilaian } \\
\text { (a) }\end{array}$ & $\begin{array}{c}\text { Bobot } \\
\text { (b) }\end{array}$ & Nilai & $\begin{array}{l}\text { Skor } \\
\text { (axb) }\end{array}$ \\
\hline 1 & Suhu $\left({ }^{\circ} \mathrm{C}\right)$ & $30-33$ & \multirow[t]{2}{*}{ (n) } & 3 & 3 & 9 \\
\hline 2 & Salinitas (ppt) & $25-26$ & & 3 & 3 & 9 \\
\hline 3 & $\mathrm{pH}$ Air & $6.8-7.5$ & \multirow{5}{*}{3} & 2 & 3 & 6 \\
\hline 4 & DO $(\mathrm{mg} / \mathrm{l})$ & $5.5-5.9$ & & 3 & 5 & 15 \\
\hline 5 & Amonia $(\mathrm{mg} / \mathrm{l})$ & 0.2 & & 2 & 5 & 10 \\
\hline 6 & Nitrat $(\mathrm{mg} / \mathrm{l})$ & $1.4-1.5$ & & 2 & 5 & 10 \\
\hline 7 & Fosfat $(\mathrm{mg} / \mathrm{l})$ & $1-2$ & & 2 & 1 & 2 \\
\hline 8 & Tekstur Tanah & $\begin{array}{l}\text { Liat berdebu } \\
\text { (Tipe halus) }\end{array}$ & \multirow{2}{*}{1} & 2 & 5 & 10 \\
\hline \multirow[t]{3}{*}{9} & pH Tanah & $7.4-7.5$ & & 2 & 5 & 10 \\
\hline & & Total Skor & & & & 81 \\
\hline & & Kelas Kelayakan & & & & S1 \\
\hline
\end{tabular}

Tabel 5. Data Analisa Kelayakan Tambak Stasiun 2

\begin{tabular}{|c|c|c|c|c|c|c|}
\hline No & Parameter & Hasil Pengukuran & $\begin{array}{c}\text { Angka } \\
\text { Pennilaian } \\
\text { (a) }\end{array}$ & $\begin{array}{l}\text { Bobot } \\
\text { (b) }\end{array}$ & Nilai & $\begin{array}{l}\text { Skor } \\
\text { (axb) }\end{array}$ \\
\hline 1 & Suhu $\left({ }^{\circ} \mathrm{C}\right)$ & $31-33$ & \multirow[t]{2}{*}{ (a) } & 3 & 3 & 9 \\
\hline 2 & Salinitas (ppt) & $21-22$ & & 3 & 5 & 15 \\
\hline 3 & $\mathrm{pH}$ Air & $6.6-6.9$ & \multirow{5}{*}{3} & 2 & 3 & 6 \\
\hline 4 & $\mathrm{DO}(\mathrm{mg} / \mathrm{l})$ & $5.7-5.9$ & & 3 & 5 & 15 \\
\hline 5 & Amonia (mg/l) & 0.3 & & 2 & 3 & 6 \\
\hline 6 & Nitrat $(\mathrm{mg} / \mathrm{l})$ & 1.8 & & 2 & 5 & 10 \\
\hline 7 & Fosfat $(\mathrm{mg} / \mathrm{l})$ & 1 & & 2 & 1 & 2 \\
\hline 8 & Tekstur Tanah & $\begin{array}{l}\text { Pasir berlempung } \\
\text { (Tipe kasar) }\end{array}$ & \multirow[t]{2}{*}{1} & 2 & 1 & 3 \\
\hline 9 & $\mathrm{pH}$ Tanah & 7,2 & & 2 & 5 & 10 \\
\hline & & Total Skor & & & & 76 \\
\hline & & Kelas Kelayakan & & & & S2 \\
\hline
\end{tabular}

Tabel 6. Data Analisa Kelayakan Tambak Stasiun 3

\begin{tabular}{clcccccc}
\hline No & Parameter & Hasil Pengukuran & $\begin{array}{c}\text { Angka } \\
\text { Pennilaian } \\
(\mathbf{a})\end{array}$ & $\begin{array}{c}\text { Bobot } \\
(\mathbf{b})\end{array}$ & Nilai & $\begin{array}{c}\text { Skor } \\
(\mathbf{a x b})\end{array}$ \\
\cline { 1 - 2 } 1 & Suhu $\left({ }^{\circ} \mathrm{C}\right)$ & 5 & & 3 & 3 & 9 \\
\cline { 1 - 2 } 2 & Salinitas (ppt) & $18-19$ & & 3 & 5 & 15 \\
\hline 3 & pH Air & $7.5-7.7$ & & 2 & 5 & 10 \\
\hline
\end{tabular}




\begin{tabular}{|c|c|c|c|c|c|c|}
\hline 4 & $\mathrm{DO}(\mathrm{mg} / \mathrm{l})$ & $4.1-4.6$ & \multirow{4}{*}{3} & 3 & 5 & 15 \\
\hline 5 & Amonia (mg/l) & 0.1 & & 2 & 5 & 10 \\
\hline 6 & Nitrat $(\mathrm{mg} / \mathrm{l})$ & 1.7 & & 2 & 5 & 10 \\
\hline 7 & Fosfat (mg/l) & 1 & & 2 & 1 & 2 \\
\hline 8 & Tekstur Tanah & $\begin{array}{l}\text { Liat berpasir } \\
\text { (Tipe sedang) }\end{array}$ & \multirow[t]{2}{*}{1} & 2 & 3 & 6 \\
\hline 9 & pH Tanah & $7.2-7.3$ & & 2 & 5 & 10 \\
\hline & & Total Skor & & & & 87 \\
\hline & & Kelas Kelayakan & & & & S1 \\
\hline
\end{tabular}

Tabel 7. Data Analisa Kelayakan Tambak Stasiun 4a

\begin{tabular}{|c|c|c|c|c|c|c|}
\hline No & Parameter & Hasil Pengukuran & $\begin{array}{c}\text { Angka } \\
\text { Pennilaian } \\
\text { (a) }\end{array}$ & $\begin{array}{l}\text { Bobot } \\
\text { (b) }\end{array}$ & Nilai & $\begin{array}{l}\text { Skor } \\
\text { (axb) }\end{array}$ \\
\hline 1 & Suhu $\left({ }^{\circ} \mathrm{C}\right)$ & $31-34$ & \multirow[t]{3}{*}{ 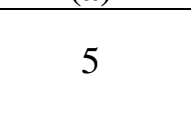 } & 3 & 1 & 3 \\
\hline 2 & Salinitas (ppt) & $24-26$ & & 3 & 3 & 9 \\
\hline 3 & pH Air & $7.8-7.9$ & & 2 & 5 & 10 \\
\hline 4 & $\mathrm{DO}(\mathrm{mg} / \mathrm{l})$ & $3.0-4.0$ & \multirow{4}{*}{3} & 3 & 3 & 9 \\
\hline 5 & Amonia (mg/l) & 0.2 & & 2 & 5 & 10 \\
\hline 6 & Nitrat $(\mathrm{mg} / \mathrm{l})$ & 1.6 & & 2 & 5 & 10 \\
\hline 7 & Fosfat (mg/l) & 1 & & 2 & 1 & 2 \\
\hline 8 & Tekstur Tanah & $\begin{array}{l}\text { Liat berpasir } \\
\text { (Tipe sedang) }\end{array}$ & \multirow{2}{*}{1} & 2 & 3 & 6 \\
\hline 9 & pH Tanah & 7,3 & & 2 & 5 & 10 \\
\hline & & Total Skor & & & & 69 \\
\hline & & Kelas Kelayakan & & & & $\mathbf{S 2}$ \\
\hline
\end{tabular}

Tabel 8. Data Analisa Kelayakan Tambak Stasiun 4b

\begin{tabular}{|c|c|c|c|c|c|c|}
\hline No & Parameter & Hasil Pengukuran & $\begin{array}{c}\text { Angka } \\
\text { Pennilaian } \\
\text { (a) }\end{array}$ & $\begin{array}{l}\text { Bobot } \\
\text { (b) }\end{array}$ & Nilai & $\begin{array}{l}\text { Skor } \\
\text { (axb) }\end{array}$ \\
\hline 1 & Suhu $\left({ }^{\circ} \mathrm{C}\right)$ & $31-34$ & \multirow{3}{*}{ (a) } & 3 & 3 & 9 \\
\hline 2 & Salinitas (ppt) & $26-27$ & & 3 & 3 & 9 \\
\hline 3 & pH Air & $6.3-6.5$ & & 2 & 3 & 6 \\
\hline 4 & $\mathrm{DO}(\mathrm{mg} / \mathrm{l})$ & $4.0-4.8$ & \multirow{4}{*}{3} & 3 & 5 & 15 \\
\hline 5 & Amonia (mg/l) & 0.2 & & 2 & 5 & 10 \\
\hline 6 & Nitrat $(\mathrm{mg} / \mathrm{l})$ & $1.5-1.6$ & & 2 & 5 & 10 \\
\hline 7 & Fosfat (mg/l) & 1 & & 2 & 1 & 2 \\
\hline 8 & Tekstur Tanah & $\begin{array}{c}\text { Liat } \\
\text { (Tipe halus) }\end{array}$ & \multirow[t]{2}{*}{1} & 2 & 5 & 10 \\
\hline 9 & $\mathrm{pH}$ Tanah & $7.0-7.2$ & & 2 & 5 & 10 \\
\hline & & Total Skor & & & & 81 \\
\hline & & Kelas Kelayakan & & & & S2 \\
\hline
\end{tabular}

Tabel 9. Kelas Kelayakan Lahan Tambak di Kelurahan Degayu

\begin{tabular}{cc}
\hline Stasiun & Total Skor \\
\hline 1 & 81 \\
\hline 2 & 76 \\
\hline 3 & 87 \\
\hline $4 \mathrm{a}$ & 69 \\
\hline $4 \mathrm{~b}$ & 81 \\
\hline Total & 394 \\
\hline Rata-rata & 78,8 \\
\hline Kelas Kelayakan & $\mathbf{S 1}$ \\
\hline
\end{tabular}




\subsection{Nilai Suhu}

Hasil pengukuran di lapangan menunjukkan nilai suhu di 4 stasiun berkisar antara $31-34^{\circ} \mathrm{C}$, suhu tertinggi ditemukan pada stasiun $4 \mathrm{a} \& 4 \mathrm{~b}$. Hal ini disebabkan pengukuran dilakukan saat siang dan sore hari, namun nilai ini masih dikatakan normal untuk budidaya kepiting hal ini sesuai dengan pendapat Cholik (1999) yang menyatakan suhu yang baik untuk pertumbuhan kepiting bakau yaitu berkisar $28-33^{\circ} \mathrm{C}$ dan jika suhu air dibawah $20^{\circ} \mathrm{C}$ maka pertumbuhan kepiting bakau lambat.

\subsection{Nilai Salinitas}

Hasil pengukuran di lapangan menunjukkan nilai salinitas di 4 stasiun berkisar antara 18-28 ppt, salinitas tertinggi dijumpai pada stasiun 4b. Hal ini diduga sebagai akibat dari pengukuran yang dilakukan pada saat musim kemarau yang dapat menyebabkan tingginya laju penguapan yang dapat mempertinggi salinitas. Brotowidjoyo et al (1995) perubahan salinitas tidak langsung berpengaruh terhadap perilaku biota tetapi berpengaruh terhadap perubahan sifat kimia air, namun nilai ini masih dikatakan normal untuk budidaya kepiting hal ini sesuai dengan pendapat Ramelan (1994) bahwa kepiting bakau dalam budidaya di tambak akan tumbuh dengan baik pada kisaran salinitas 15 - 25 ppt. Pada kisaran salintas 35 - 40 ppt, kepiting akan mengalami pertumbuhan yang lambat. Perubahan salinitas dapat mempengaruhi konsumsi oksigen, sehingga mempengaruhi laju metabolisme dan aktivitas suatu organisme (Buwono, 1993).

\subsection{Nilai pH Air}

Hasil pengukuran di lapangan menunjukkan nilai $\mathrm{pH}$ air di 4 stasiun berkisar antara 6,3-7,9 ppm. Nilai $\mathrm{pH}$ dalam suatu perairan dipengaruhi oleh beberapa faktor antara lain kegiatan fotosintesis, suhu dan terdapatnya anion dan kation (Supriharyono, 1978). Kisaran nilai ini masih dikatakan normal untuk budidaya kepiting hal ini sesuai dengan pendapat Siahainenia (2008) bahwa perairan yang memiliki kisaran $\mathrm{pH}$ 6,507,50 dikategorikan perairan yang cukup baik bagi kepiting bakau (Scylla spp.), sedangkan perairan dengan kisaran $\mathrm{pH}$ 7,50 - 9 di kategorikan sangat baik untuk pertumbuhan kepiting bakau (Christensen et al., 2005; Romano and Zeng, 2007; Shelley and Lovatelli, 2011).

\subsection{Nilai DO}

Hasil pengukuran di lapangan menunjukkan nilai DO di 4 stasiun berkisar antara 3,0-6,0 ppm, salinitas terendah dijumpai pada stasiun 4a. Hal ini diduga sebagai akibat dari pengukuran yang dilakukan pada saat cuaca panas yang menyebabkan menurunnya DO, hal ini sesuai dengan pendapat Odum (1996), dimana kadar oksigen dalam air akan bertambah dengan semakin rendahnya suhu.,Namun nilai ini masih dikatakan normal untuk budidaya kepiting hal ini sesuai dengan pendapat Ramelan (1994) kepiting bisa tumbuh dan berkembang dengan baik ditambak dengan kadar oksigen terlarut tidak kurang dari $4 \mathrm{mg} / \mathrm{l}$, kepiting akan mengalami stress bila kadar oksigen terlarut dalam tambak $<2 \mathrm{mg} / \mathrm{l}$. udang dan ikan pada umumnya akan hidup dan tumbuh dengan baik pada kadar oksigen terlarut di atas 3,0 mg/L (Boyd,1996). Bila konstrasi oksigen terlarut $<3 \mathrm{mg} / \mathrm{l}$, maka nafsu makan kultivan akan berkurang dan tidak dapat berkembang dengan baik (Buwono, 1993). 


\subsection{Nilai Amonia}

Hasil pengukuran di laboratorium menunjukkan nilai amonia di 4 stasiun berkisar antara 0,1-0,3 mg/l, kisaran nilai ini masih dikatakan normal untuk budidaya kepiting hal ini sesuai menurut Keputusan Men KLH No. 51 tahun 2004 bahwa standar baku mutu untuk NH3 baiknya dibawah $0,3 \mathrm{mg} / \mathrm{L}$ (biota laut). Amonia tertinggi dijumpai pada stasiun 2, tingginya amonia ini diduga akibat rembesan dari jalur pembuangan air budidaya udang yang masuk kedalam tambak karena pada stasiun 2 memiliki tekstur pasir. Menurut Kordi (2005), sumber utama ammonia (NH3) berasal dari sisa pakan, kotoran organisme budidaya dan dekomposisi sisa plankton yang mati. Agar kepiting tumbuh cukup baik, amoniak yang terdapat dalam air tambak tidak boleh lebih dari 2 ppm (Rusmiyati, 2015). Menurut Boyd (1990) amonia dan amonium bersifat toksik tetapi amonia lebih bersifat toksik daripada amonium.

\subsection{Nilai Nitrat}

Hasil pengukuran di laboratorium menunjukkan nilai nitrat di 4 stasiun berkisar antara 1,4-1,8 mg/l, kisaran nilai ini masih dikatakan normal untuk budidaya kepiting karena masih memenuhi standar mutu yang ditetapkan PP No.82 tahun 2001 tentang Pengelolaan Kualitas Air dan Pengendalian Pencemaran Air yaitu tidak lebih dari $20 \mathrm{mg} / \mathrm{L}$. Hutagalung dan Rozak (1997) menyatakan bahwa peningkatan kadar nitrat di perairan disebabkan oleh masuknya limbah domestik atau pertanian (pemupukan) yang umumnya banyak mengandung nitrat. Fitoplankton dapat tumbuh optimal pada kandungan nitrat sebesar 0,9 - 3,5 mg/l (Oktora, 2000).

\subsection{Nilai Fosfat}

Hasil pengukuran di laboratorium menunjukkan nilai fosfat di 4 stasiun berkisar antara 1-2 mg/l, kisaran nilai tersebut kurang baik untuk budidaya kepiting karena kandungan PO4 jarang melebihi $0,1 \mathrm{mg} / \mathrm{L}$, meskipun pada perairan eutrof kandungan PO4 pada perairan alami jarang melebihi $1 \mathrm{mg} / \mathrm{L}$ (Boyd, 1995). Tingginya nilai fosfat di 4 stasiun diduga karena sumber air yang digunakan berasal dari kali susukan sampai kali warungasem ysng mengandung limbah tinggi ditandai dengan air berwarna hitam di sepanjang kali Warungasem hal ini sesuai dengan pendapat Hutagalung dan Rozak (1997), bahwa keberadaan fosfat yang tinggi disebabkan oleh masuknya limbah domestik, pertanian, industri dan perikanan yang mengandung fosfat. Fosfat merupakan bentuk fosfor yang dapat dimanfaatkan oleh tumbuhtumbuhan (Dugan, 1972). Konsentrasi fosfat yang tinggi dapat terjadi karena suatu proses ekresi oleh ikan dalam bentuk feces, sehingga fosfor dalam bentuk ini dapat mengendap di dasar perairan dan terakumulasi di sedimen, atau limbah yang masuk kedalam tambak dan bercampur dengan pupuk yang mengandung unsur fosfor biasanya digunakan oleh petambak adalah faktor yang mempengaruhi kadar fosfat pada tambak tersebut.

\subsection{Tekstur Tanah}

Hasil pengukuran di laboratoium terhadap tekstur tanah di 4 stasiun secara umum didominasi oleh campuran antara lempung/liat, pasir, dan debu, tekstur tersebut dikatakan baik untuk budidaya kepiting. Tekstur tanah yang baik untuk tambak adalah: liat, lempung berliat, lempung liat berdebu, lempung berdebu, lempung dan lempung liat berpasir (Ilyas et al., 1987). Pada stasiun 2 tekstur bertipe kasar hal ini menurut Boyd (1995) tambak dengan tanah bertekstur kasar seperti pasir berlempung dan pasir 
memiliki tingkat porositas yang tinggi, sebagai akibatnya tambak tidak bisa menahan air. Tanah tambak sering dijumpai bertekstur halus dengan kandungan liat minimum 20-30\% untuk menahan peresapan ke samping.

\subsection{Nilai pH Tanah}

Hasil pengukuran di laboratorium menunjukkan nilai $\mathrm{pH}$ tanah di 4 stasiun berkisar antara 7,0-7,5, kisaran nilai ini dikatakan sangat baik untuk budidaya kepiting hal ini sesuai pendapat William A.W (2003) yang mengatakan kriteria yang harus dipenuhi dalam budidaya kepiting lumpur/bakau di tambak untuk $\mathrm{pH}$ tanah yaitu 5,57,5 .

\subsection{Analisis Kesesuaian Lahan Tambak Di Kelurahan Degayu}

Hasil penilaian kesesuaian lahan tambak berdasarkan interval kelayakan (S1; S2; S3) didapatkan bahwa parameter air dan tanah di 4 stasiun tambak termasuk dalam kategori baik dengan total skor berturut-turut yaitu $81 ; 76 ; 87 ; 69 ; 81$ dengan skor ratarata 78,8, stasiun 3 memiliki total skor tertinggi sedangkan total skor terendah didapat stasiun 2. Dengan demikian ke-4 stasiun pengamatan yang mewakili tambak di Kelurahan Degayu memiliki kategori kelas kelayakan yang sangat sesuai (S1) untuk mendukung aktivitas budidaya kepiting bakau.

\section{SIMPULAN}

Berdasarkan hasil penelitian yang dilaksanakan dapat disimpulkan bahwa :

a) Pada stasiun 1,3, dan 4b mendapat nilai $\mathrm{S} 1$ (sangat sesuai) yang artinya tambak ini sangat sesuai untuk budidaya kepiting bakau.

b) Pada stasiun tambak 2 dan 4 a mendapat nilai S2 (sesuai) yang artinya tambak ini sesuai untuk budidaya kepiting bakau.

c) Tambak Kelurahan Degayu memiliki kategori kelas kelayakan yang sangat sesuai (S1) untuk mendukung aktivitas budidaya kepiting bakau.

\section{SARAN}

Perlu dilakukan penelitian lanjutan tentang analisis kesesuaian lahan tambak berdasarkan sifat biologis.

\section{DAFTAR PUSTAKA}

Adhikari, S. 2003. Fertilization soil and water quality management in small scale ponds: Fertilization require Aqua-asia magazine vol: Oct-2003

Agus, M. 2008. Tesis: Analisis Carryng Capacity Tambak Pada Sentra. Budidaya Kepiting Bakau (Scylla Sp) Di Kabupaten Pemalang - Jawa. Tengah. Program Pascasarjana Undip. Semarang

Boyd, C.E. 1990. Water Quality in Pond for Aquaculture. Department of Fisheries and Allied Aquacultures. Auburn University, Alabama, USA

Boyd, C.E. 1995. Bottom Soil, Sediment, and Pond Aquaculture. Chapman and Hall, New York, $348 \mathrm{pp}$.

Boyd, C.E. 1996. Water quality in pond for aquaculture. Auburn University. Alabama. 
BPS. 2017. Ekspor Kepiting dan Kerang-Kerangan Menurut Negara Tujuan Utama, 2002 2015.

Brotowidjoyo, M.D, Dj. Tribawono, E. Mulbyantoro, 1995. Pengantar Lingkungan Perairan dan Budidaya Air. Penerbit Liberty, Yogyakarta.

Buwono,I.D,. 1993. Tambak Udang Windu Sistem Pengelolaan Intensif. Kanisius. Yogyakarta.

Cholik, F. 1999. Review of Mud Crab Culture Research in Indonesia. In Mud Crab Aquaculture and Biology. ACIAR Procceding No. 78. Canberra. Australia.

Christensen, S.M., D.J. Macintosh, and N.T. Phuong. 2005. Pond roduction of the mud crab Scylla paramamosain (Estampador) and S. Olivacea (Herbst) in the Mekong Delta, Vietnam using two different supple-mentary diets. Aqua.Res., 35:1013-1024.

Dugan, P.R., 1972, Biochemical Ecology of Water Pollution, Plenum Press. New York, 159 p.

Hutagalung, Horas dan Abdul Rozak. 1997. Metode Analisis Air Laut, Sedimen dan Biota. Buku Kedua. Puslitbang Oseanologi-LIPI. Jakarta.

Ilyas, S., Cholik, F., Poernomo, A., Ismail, W., Arifudin, R., Daulay, T., Ismail, A., Koesoemadinata, S., Rabegnatar, I N.S., Soepriyadi, H., Suharto, H.H., Azwar, Z.I., \& Ekowardoyo, S. 1987. Petunjuk Teknis bagi Pengoperasian Unit Usaha Pembesaran Udang Windu. Pusat Penelitian dan Pengembangan Perikanan, Jakarta,100 hlm.

Irianto, A. 2007. Statistik Konsep Dasar dan Aplikasinya. Penerbit Kencana. Jakarta. 312 hlm

Karthik, M., J. Suri, N. Saharan, and R.S. Biradar. 2005. Brackish water aquaculture site selection in Palghar Taluk, Thane District of Maharashtra, India, using the techniques of remote sensing and geographical information system. Aquacultural Engineering, 32:285-302.

Kementerian Lingkungan Hidup Republik Indonesia (KLH). 2004. Baku Mutu Air Laut untuk Biota Laut. Keputusan Menteri Negara Lingkungan Hidup No 51 Tahun 2004 Tentang Baku Mutu Air Laut, KLH. Jakarta

Kordi. 2005. Budidaya Ikan Beronang. Penerbit Rineka Cipta. Jakarta

Mossa, K., I.Aswandy dan A.Kasry. 1995. Kepiting Bakau Scylla serrata dariPerairan Indonesia. LON - LIPI. 18 hal.

Nasir, M., 1983. Metode Penelitian. Ghalia Indonesia, Jakarta. 622 hal.

Odum, Eugene P. 1996. Dasar-dasar Ekologi; Edisi Ketiga.Yogyakarta. Gadjah Mada University Press, Penerjemah Samingan, Tjahjono.

Oktora, A.D. 2000. Kajian Produktivitas Primer Berdasarkan Kandungan Klorofil pada Perairan Tambak Berbakau dan Tidak Berbakau di Desa Grinting, Kabupaten Brebes [Skripsi]. Jurusan Perikanan Fakultas Perikanan dan Ilmu Kelautan. Universitas Diponegoro. Semarang

Peraturan Pemerintah Republik Indonesia Nomor 82 Tahun 2001 Tentang Pengelolaan Kualitas Air dan Pengendalian Pencemaran Air. Sekretaris Negara Republik Indonesia. Jakarta 
Pérez, O.M., Ross, L.G., Telfer, T.C., \& del Campo Barquin, L.M. 2003. Water quality requirements for marine fish cage site selection in Tenerife (Canary Islands): predictive modelling and analysis using GIS. Aquaculture, 224: 51-68.

Prahasta E. 2002. Konsep Konsep Dasar Informasi Geografis. Informatika. Bandung

Ramelan H.S. 1994. Pembenihan Kepiting Bakau (Scylla serrata). Direktorat Bina Perbenihan. Direktorat Jenderal Perikanan. Jakarta

Romano N \& Zeng C. 2006. The effects of salinity on the survival, growth and haemolymph osmolality of early juvenile blue swimmer crabs, Portunus pelagicus. Aquaculture. 260 (2006) 151-162.

Rossiter, D.G. 1996. A theoretical framework for land evaluation. Geoderma, 72: 165- 202.

Rusmiyati, Sri. 2015. Sukses Budidaya Kepiting Soka dan Kepiting Telur. Penerbit Pustaka Baru Press. Yogyakarta

Shelley, C., Lovatelli, A.(2011). Mud crab aquaculture, a practical manual.FAO, Fisheries and aquaculture technical paper 567.FAO, Rome, Italy.

Siahainenia L. 2008. Bioekologi kepiting bakau (Scylla spp.) di ekosistem mangrove Kabupaten Subang, Jawa Barat [disertasi]. Sekolah Pascasarjana, Institut Pertanian Bogor. Bogor. 289 hlm

Supriharyono. 1978. Kondisi Kualitas Air di Saluran-saluran di daerah-daerah persawahan, persawahan-pemukiman dan pemukiman, Delta Upang Sumatera Selatan. Program Pasca Sarjana IPB. Bogor

William, A. W., 2003. Aquaculture Site Selection. Kentucky State University Coorporative Extention Progam. Princeton. 